\title{
Mix Design for Pervious Recycled Aggregate Concrete
}

\author{
Rasiah Sriravindrarajah"1), , Neo Derek Huai Wang ${ }^{2)}$, and Lai Jian Wen Ervin²)
}

(Received August 29, 2012, Accepted November 6, 2012, Published online November 27, 2012)

\begin{abstract}
Pervious concrete is a tailored-property concrete with high water permeability which allow the passage of water to flow through easily through the existing interconnected large pore structure. This paper reports the results of an experimental investigation into the development of pervious concrete with reduced cement content and recycled concrete aggregate for sustainable permeable pavement construction. High fineness ground granulated blast furnace slag was used to replace up to $70 \%$ cement by weight. The properties of the pervious concrete were evaluated by determining the compressive strength at 7 and 28 days, void content and water permeability under falling head. The compressive strength of pervious concrete increased with a reduction in the maximum aggregate size from 20 to $13 \mathrm{~mm}$. The relationship between 28-day compressive strength and porosity for pervious concrete was adversely affected by the use of recycled concrete aggregate instead of natural aggregate. However, the binder materials type, age, aggregate size and test specimen shape had marginal effect on the strength-porosity relationship. The results also showed that the water permeability of pervious concrete is primarily influenced by the porosity and not affected by the use of recycled concrete aggregate in place of natural aggregate. The empirical inter-relationships developed among porosity, compressive strength and water permeability could be used in the mix design of pervious concrete with either natural or recycled concrete aggregates to meet the specification requirements of compressive strength and water permeability.
\end{abstract}

Keywords: pervious concrete, porosity, strength, permeability, recycled concrete aggregate, mix design.

\section{Introduction}

In recent times, major cities around the world have experienced frequent flooding due to the combination of increased rainfall and reduced in permeable surface areas. With the increasing amount of built infrastructures such as residential and commercial buildings and decreasing permeable unpaved open areas, the stormwater runoff is rapidly increased. As a consequence, the drainage system gets overloaded and flash flooding becomes inevitable, thus causing disruption to the road transport and flooding of basement car parks and shopping centres. In order to manage the stormwater runoff in urban areas, an engineered solution is needed to avoid flash flooding.

The use of pervious concrete for the construction of secondary roads, parking lots, driveways, walkways and sidewalks is increasing in the USA. By capturing a significant amount of stormwater and allowing it to seep into the ground, the pervious concrete is instrumental in recharging

\footnotetext{
${ }^{1)}$ School of Civil and Environmental Engineering, University of Technology, Sydney, NSW, Australia. *Corresponding Author;

E-mail: Sri.Ravindrarajah@uts.edu.au

${ }^{2}$ School of Civil and Environmental Engineering, Nanyang Technological University, Singapore, Singapore.
}

Copyright $($ The Author(s) 2012. This article is published with open access at Springerlink.com groundwater and reducing stormwater runoff. With a combination of structural and hydrological design with the use of pervious concrete for pavement construction provided the best solution to stormwater management, as recognised by the US Environmental Protection Agency (Stormwater management handbook, US Environmental Protection Authority 2009).

Pervious concrete is a special type of concrete with a high proportion of large sized pores, typically $2-8 \mathrm{~mm}$. The typical porosity of pervious concrete ranged from 15 to $30 \%$ and the presence of interconnected large pores system allows the water to flow easily through the pervious concrete (ACI 2006). The pervious concrete mixes should meet the specification requirements for permeable concrete pavements. Typical pervious concrete mix consists of $180-355 \mathrm{~kg} / \mathrm{m}^{3}$ of binder material, $1420-1600 \mathrm{~kg} / \mathrm{m}^{3}$ of coarse aggregate and water to cement ratio ranged from 0.27 to 0.43 . The typical 28-day compressive strength ranges from 5.6 to $21.0 \mathrm{MPa}$, with void ratios ranging from 14 to $31 \%$, and permeability coefficient varies from 0.25 to $6.1 \mathrm{~mm} / \mathrm{s}$ (Schaefer et al. 2006). Previous studies have reported the influence of water-to-cement ratio, aggregate-tocement ratio, aggregate sizes, and binder material type on the strengths of pervious concretes (Tennis et al. 2004; Malhotra 1976; Meininger 1988; Otani et al. 2005). The properties of pervious concrete having various mix compositions were reported elsewhere (Sriravindrarajah and Aoki 2008; Aoki and Sriravindrarajah 2008; Aoki et al. 2008; Aoki et al. 2009; Sriravindrarajah et al. 2010; Aoki et al. 2012). The 
permeability was $15 \mathrm{~mm} / \mathrm{s}$ for pervious concrete having the compressive strength of $10 \mathrm{MPa}$. The drying shrinkage of pervious concrete is lower than that for structural concrete (Aoki and Sriravindrarajah 2008; Sriravindrarajah et al. 2010; Aoki et al. 2012).

Table 1 shows the effect of replacing 20 and $50 \%$ of cement with fly ash on the properties of pervious concrete. At $50 \%$ cement replacement with fly ash, the compressive strength of pervious concrete was reduced by $44 \%$ but the permeability was marginally improved, when compared with the corresponding properties of pervious concrete without cement replacement. The 56-day free drying shrinkage was decreased by $21 \%$ and the compressive strength of pervious concrete is closely related to the porosity of concrete.

In order to achieve environmental sustainability, the use of recycled concrete aggregate in structural and semi-structural concrete mixes is not uncommon. Recycled concrete aggregate has lower strength, stiffness and high water absorption due to the presence of weak attached mortar to the natural aggregate. In 1985, Sriravindrarajah and Tam reported that partial replacement of natural coarse aggregate with recycled concrete aggregate in medium strength concrete had reduced the compressive and tensile strengths and modulus of elasticity and increased the drying shrinkage of concrete. Adjustments to the mix composition and addition of supplementary cementitious materials such as fly ash and silica fume could be easily used to improve the compressive strength (Sriravindrarajah and Tam 1988). However, reduced modulus of elasticity and increased shrinkage and creep of concrete with recycled concrete aggregate are unavoidable due to the poor mechanical properties of recycled concrete aggregate compared to natural aggregate. Sriravindrarajah et al. (2001) showed that quality variation of commercially recycled coarse aggregate had limited influence on the variability of the properties of recycled aggregate concrete.

Otani et al. (2005) studied the strength of pervious concrete with four types of aggregates, namely natural, recycled concrete, blast-furnace and artificial lightweight. The results showed that the strength of pervious concrete is affected by the density of aggregate. At a given porosity, the use of low modulus aggregate produced a significant reduction in the compressive strength. They also found that the type of cement had marginal effect on the strength of pervious concrete having the same void content. Murao et al. (2002) reported that the strength of pervious concrete at a given porosity is reduced when the recycled aggregate is from $15 \mathrm{MPa}$ concrete compared to that from $25 \mathrm{MPa}$ concrete.

This paper discusses the results of an experimental investigation into the properties of pervious concrete with natural aggregate and recycled concrete aggregate with ground granulated blast furnace slag as a cement replacement material up to $70 \%$ by weight. The investigated properties of pervious concrete are compressive strength development with age, porosity and water permeability. The results obtained are used to develop inter-relationships among porosity, compressive strength and water permeability, needed for the mix design of pervious concrete mixes with either natural aggregate or recycled concrete aggregate.

\section{Experimental Details}

\subsection{Materials and Mix Proportions}

Binder materials used in pervious concrete mixes were Ordinary Portland cement (OPC) and ground granulated blast furnace slag (GGBFS). The fineness of the cement and GGBFS was 360 and $870 \mathrm{~m}^{2} / \mathrm{kg}$, respectively. The strength activity index for GGBFS was 1.64, 1.20 and 1.16 at 3, 7 and 28 days, respectively.

Two single-sized coarse aggregate ranging from either 5 to $13 \mathrm{~mm}$ or 13 to $20 \mathrm{~mm}$ were used in pervious concrete mixes. The commercially available aggregates were either natural aggregate (granite) or recycled concrete aggregate, as shown in Fig. 1. The specific gravity of the natural aggregate was 2.65 and that for recycled concrete aggregate was 2.19 and 2.04 for 20 and $13 \mathrm{~mm}$ maximum size recycled concrete aggregate, respectively. The water absorption for 20 and $13 \mathrm{~mm}$ recycled concrete aggregates was 5.3 and $8.2 \%$, respectively, compared to $1.0 \%$ for the natural aggregate. High water absorption and lower specific gravity for $13 \mathrm{~mm}$ recycled concrete aggregate are due to increased amount of weak attached mortar compared to that for $20 \mathrm{~mm}$ recycled concrete aggregate. Fine aggregate was deliberately omitted in the mixes to create large open textured porous concrete.

Table 2 summarises the compositions of pervious concrete mixes. The cement replacement levels with GGBFS were 0 , 35 and $70 \%$, by weight. The maximum aggregate sizes, 13 and $20 \mathrm{~mm}$, were used in the concrete mixes and the aggregate was either natural or recycled concrete. The aggregate to binder ratio for concrete mix with $20 \mathrm{~mm}$ aggregate was 5.0 and 4.0, by weight for natural and recycled aggregates, respectively. The aggregate to binder ratio was reduced to 3.7 and 2.8 , respectively when $13 \mathrm{~mm}$ aggregate size was used, to maintain the same theoretical void content of $20 \%$.

The natural and recycled aggregates were saturated in water for more than $24 \mathrm{~h}$ and removed from water an hour

Table 1 Properties of fly ash pervious concrete (Aoki et al. 2012).

\begin{tabular}{|c|c|c|c|c|c|}
\hline Cement $(\%)$ & Fly ash (\%) & Porosity (\%) & Strength (MPa) & Permeability $(\mathrm{mm} / \mathrm{s})$ & $\begin{array}{c}\text { 56-Day shrinkage } \\
\left(\times 10^{-6}\right)\end{array}$ \\
\hline 100 & 0 & 36 & 10.1 & 14.9 & 600 \\
\hline 80 & 20 & 33 & 8.8 & 12.1 & 550 \\
\hline 50 & 50 & 32 & 5.7 & 15.9 & 470 \\
\hline
\end{tabular}



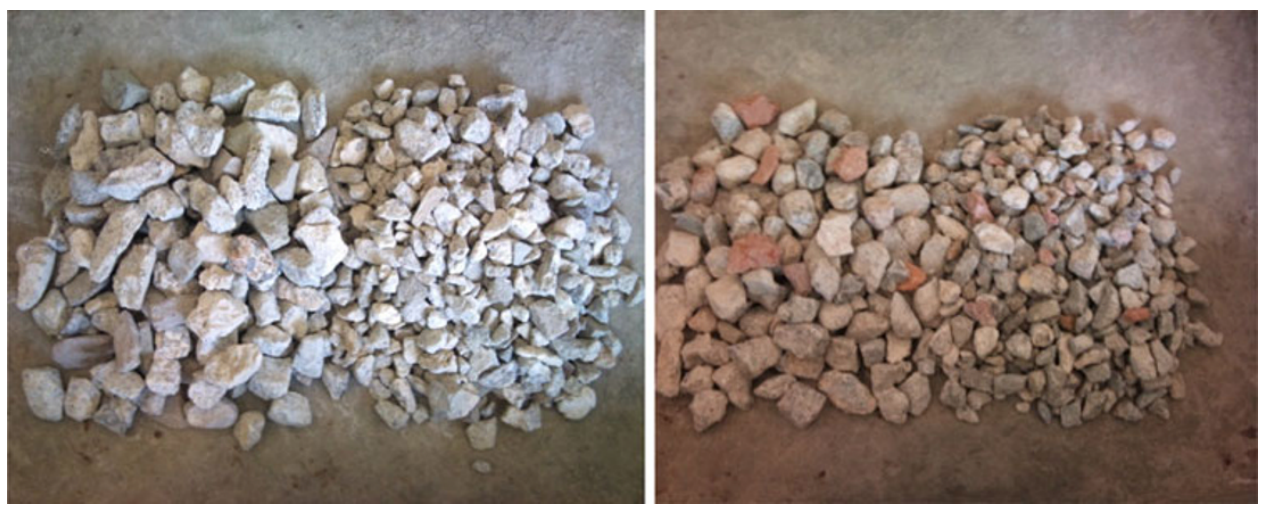

Fig. 1 Natural and recycled coarse aggregates (20 and $13 \mathrm{~mm}$ ).

Table 2 Mix details for the pervious recycled aggregate concrete.

\begin{tabular}{c|c|c|c|c|c}
\hline Mix & Cement (\%) & Slag (\%) & Agg./binder & Cement $\left(\mathrm{kg} / \mathrm{m}^{3}\right)$ & GGBFS $\left(\mathrm{kg} / \mathrm{m}^{3}\right)$ \\
\hline \hline NA20 & 100 & 0 & 5.00 & 270 & 0 \\
\hline NA13 & 100 & 0 & 3.70 & 320 & 0 \\
\hline RA20 & 100 & 0 & 4.00 & 335 & 0 \\
\hline RA13 & 100 & 0 & 2.80 & 340 & 0 \\
\hline RA13S35 & 65 & 35 & 3.00 & 230 & 124 \\
\hline RA13S70 & 30 & 70 & 3.00 & 120 & 280 \\
\hline
\end{tabular}

before the concrete mixing. The aggregates were batched in the saturated surface dry condition. The free water to binder ratio was 0.33 , by weight, was maintained for the concrete mixes. The pervious concrete mixes were found to have sufficient workability, as assessed by hand-ball rolling test (Sriravindrarajah and Aoki 2008). No chemical admixture was used in the concrete mixes.

\subsection{Concrete Mixing and Casting and Curing of Test Specimens}

The pervious concrete mixes were produced in a tilt-drum type mixer. The coarse aggregate, cement and GGBFS were initially dry mixed for a few minutes. Then, the required quantity of free water was added gradually while the mixing was in progress. The mixing was continued until the mix was found to be uniform in appearance. Immediately after mixing, the fresh concrete was tested for its wet density and the standard specimens was cast in steel moulds for hardened concrete testing. For each mix, 14 Nos. of $100 \mathrm{~mm}$ diameter by $200 \mathrm{~mm}$ high cylinders and 3 Nos. of $150 \mathrm{mmm}$ cubes were cast in layers and the moulds were gently tapped with rubber mallet to provide minimum compaction. Experience had shown that excessive vibration can cause segregation of no-fines concrete mixes. The specimens were demoulded after $24 \mathrm{~h}$ and stored in water at room temperature of $28{ }^{\circ} \mathrm{C}$ until the age of testing. The test cylinders and cubes were tested at the ages of either 7 or 28 days for the compressive strength, in accordance with the procedures given in EN 12390-3.

\subsection{Porosity of Pervious Concrete}

Porosity of hardened pervious concrete was determined using the void free density (T) and measured density (D) of the concrete mixes, using the Eq. (1)

Porosity $(\%)=100 \times(\mathrm{T}-\mathrm{D}) / \mathrm{T}$.

\subsection{Water Permeability of Pervious Concrete}

For each mix, two identical cylindrical specimens were tested under falling head for water permeability using a specially made permeability test set-up (Fig. 2). $100 \mathrm{~mm}$ diameter test cylinders were $150 \mathrm{~mm}$ high, which were obtained from $200 \mathrm{~mm}$ high standard cylinders. The specimens were wrapped with a rubber membrane to ensure that the water only flows through the cross-section of the specimen without any leaks along its edges. The specimens were fitted to an acrylic tube with a valve at the end. The top of the specimens was fitted with an acrylic tube with gradation to indicate the water head. Prior to the permeability test, the water was allowed to run freely through the specimen and the specimens were tapped to release the entrapped air in the specimens.

The water permeability test was conducted on each cylinder under four falling heads, namely 500-400 mm; 400-300 mm; 300-200 $\mathrm{mm}$ and 500-200 mm. The test was repeated for three times to improve the accuracy of the results. The coefficient of water permeability $(\mathrm{k})$ is given in the Eq. (2).

$$
\mathrm{k}=(\mathrm{aL} / \mathrm{At}) \times \ln \left(\mathrm{h}_{\mathrm{o}} / \mathrm{h}_{1}\right)
$$


where $\mathrm{a}$ is the cross-sectional area of the reservoir $\left(7857 \mathrm{~mm}^{2}\right), \mathrm{L}$ is the length of the specimen $(150 \mathrm{~mm}), \mathrm{A}$ is the cross-sectional area of the specimen $\left(\mathrm{mm}^{2}\right)$, $\mathrm{T}$ is the time taken for the head to fall from $h_{o}$ to $h_{1}, h_{o}$ is the initial water head $(500,400$ or $300 \mathrm{~mm}), \mathrm{h}_{1}$ is the final water head (400, 300 and $200 \mathrm{~mm}$ ).

\section{Results and Discussion}

Table 3 shows the porosity and cylinder strength at the ages of 7 and 28 days for all six concrete mixes. For a

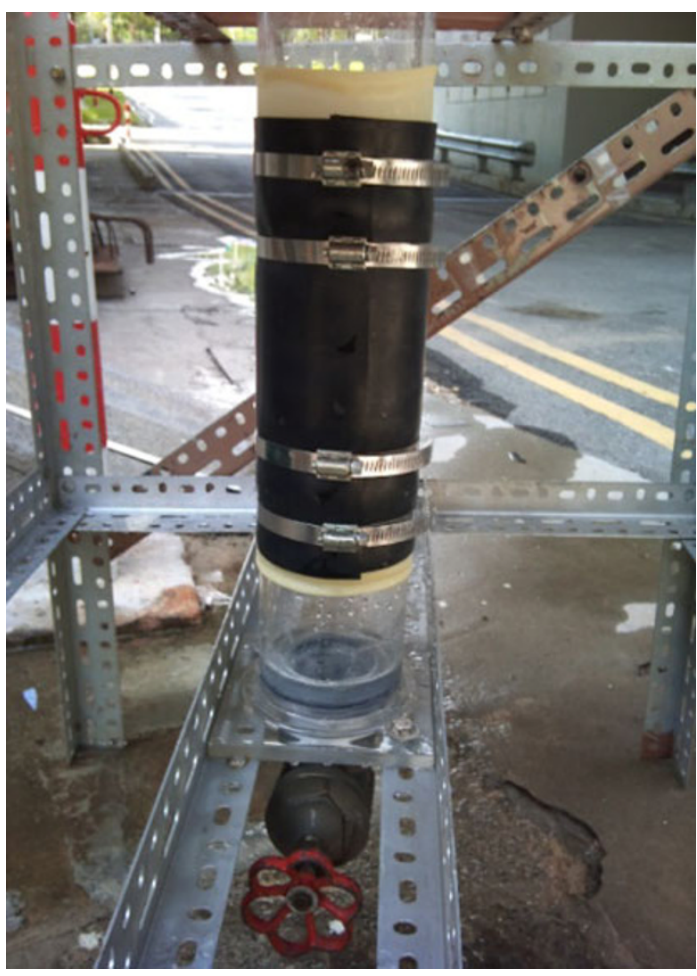

Fig. 2 Water permeability test set-up. particular concrete mix at the same age, noticeable variation in the porosity among the three cylinders was noted. This variation has affected the measured compressive strength. Nevertheless, the individual results were used to determine the mean values for porosity and compressive strength for each mix. The mean strength values were used to calculate the 28 to 7 -day compressive strength ratio. The individual 7 and 28-day strength results for the pervious concrete mixes were plotted against individual porosity in Fig. 3 .

\subsection{Effect of Binder Type and Age on the Strength of Recycled Pervious Concrete}

The results shown in Table 3 in the last column indicate that the mean strength of pervious recycled concrete is marginally increased with the age, due to the improved strength of the binder paste with time. Similar results have been reported for pervious concrete with and without fly ash (Aoki et al. 2008, 2009, 2012). However, due to the variability in the porosity of the test specimens, the strength improvement with age is difficult to determine.

Figure 3 shows that the relationship between compressive strength and porosity is not significantly affected by either age or cement replacement with GGBFS. This is as expected since the compressive strength is primarily affected by the porosity of concrete and any improvement in the cement paste strength from 7 days to 28 days can be expected to have minimum effect on the compressive strength of pervious concrete.

\subsection{Effect of Aggregate Type on the Strength of Pervious Concrete}

Figure 4 shows the relationship between 28-day cube strength and porosity for pervious concrete with natural and recycled concrete aggregates. The results from additional mixes performed at the preliminary investigation with both types of aggregates are included in the plot to improve the relationship prediction. Figure 2 shows that for a given

Table 3 Porosity and compressive cylinder strength of pervious concrete.

\begin{tabular}{|c|c|c|c|c|c|c|}
\hline Mix & Age (days) & Porosity range $(\%)$ & $\begin{array}{c}28 \text {-Day strength } \mathrm{f}_{28} \\
\text { range }(\mathrm{MPa})\end{array}$ & Mean porosity $(\%)$ & $\begin{array}{c}\text { Mean 28-day } \\
\text { strength (MPa) }\end{array}$ & $\begin{array}{c}\text { Strength ratio }\left(\mathrm{f}_{28} /\right. \\
\left.\mathrm{f}_{7}\right)\end{array}$ \\
\hline \multirow[t]{2}{*}{ NA20 } & 7 & $30.9-36.7$ & $6.16-8.53$ & 42.1 & 7.41 & 1.00 \\
\hline & 28 & $33.3-36.1$ & $6.69-7.79$ & 34.3 & 7.41 & 1.00 \\
\hline NA13 & 7 & $25.5-29.3$ & $11.1-13.1$ & 27.7 & 11.8 & 1.00 \\
\hline \multirow[t]{2}{*}{ RA20 } & 7 & $23.5-25.4$ & $6.03-6.80$ & 27.7 & 6.47 & 1.00 \\
\hline & 28 & $24.6-28.8$ & $4.48-6.96$ & 27.5 & 6.06 & 0.94 \\
\hline \multirow[t]{2}{*}{ RA13 } & 7 & $13.8-16.1$ & $6.42-12.1$ & 14.4 & 11.1 & 1.00 \\
\hline & 28 & $7.0-13.2$ & $10.4-13.3$ & 9.87 & 12.1 & 1.09 \\
\hline RA13S35 & 28 & $22.8-28.4$ & $5.09-7.00$ & 25.5 & 6.19 & 1.07 \\
\hline \multirow[t]{2}{*}{ RA13S70 } & 7 & $13.7-16.0$ & $8.55-10.8$ & 15.0 & 10.0 & 1.00 \\
\hline & 28 & $13.9-19.7$ & $10.2-11.1$ & 16.7 & 10.6 & 1.06 \\
\hline
\end{tabular}


porosity, the compressive strength of recycled pervious concrete is lower than that for the pervious natural aggregate concrete. Otani et al. (2005) showed similar drop in compressive strength for pervious recycled aggregate concrete. The difference in strength reduced with the increase in porosity. At $20-25 \%$ porosity, recycled aggregate pervious concrete is considerable weaker than the natural aggregate pervious concrete.

\subsection{Effect of Aggregate Size on Strength of Pervious Concrete}

Figures 5 and 6 show the influence on maximum aggregate size on the compressive strength of pervious concrete with recycled concrete aggregate and natural aggregate, respectively. With the increase in the aggregate size, the bulk density of aggregate is decreased and this in turn increased the porosity of concrete. Mahboub et al. (2009) reported that the porosity of pervious concrete can be estimated with the knowledge of the bulk density of aggregate, through the existing linear relationship. With the increase in the porosity, the strength of pervious concrete is reduced. Any improvement in the strength of the cement paste with time will not be able to produce any significant improvement in strength for pervious concrete.

\subsection{Effect of Shape of Test Specimens}

Compressive strength of concrete can be determined by using either cubes or cylinders. In this study, both cubes $(150 \mathrm{~mm})$ and cylinders $(100 \mathrm{~mm}$ diameter by $200 \mathrm{~mm}$ high) were used. Since the test specimens were cast with minimum compaction, the surface of the specimens was

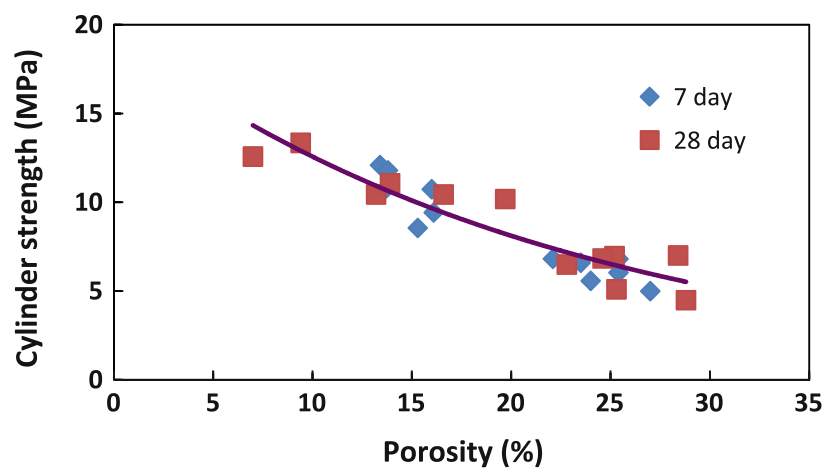

Fig. 3 Relationship between strength and porosity for recycled pervious concrete.

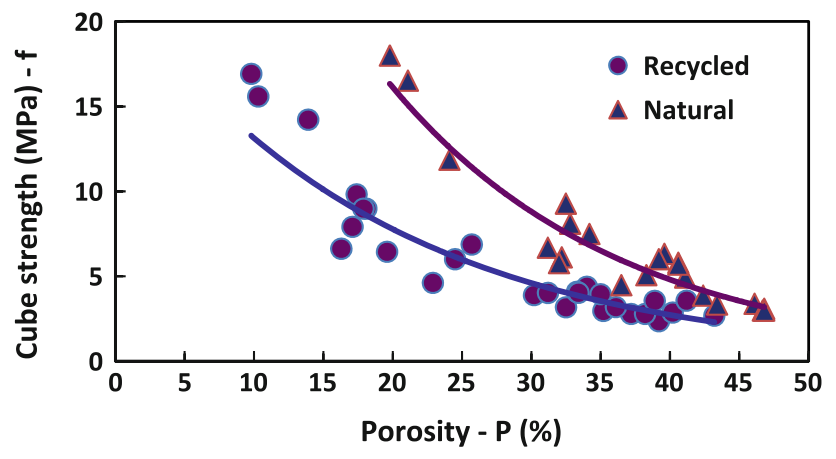

Fig. 4 Effect of aggregate type on strength of pervious concrete. honeycombed and need to be capped before the testing was carried out. Cubes are easy to handle and $150 \mathrm{~mm}$ cubes were appropriate. Further research is needed to establish the appropriate test specimen size and shape for the evaluation of compressive strength for low strength pervious concrete.

Figure 7 shows the relationship between compressive strength and porosity. Both cube and cylinder strength results were used in this plot. It is evident that the relationship between compressive strength and porosity is not significantly affected by the specimen size. This implies that $150 \mathrm{~mm}$ cubes could be used for strength testing and capping of the specimens may be needed, considering the uneven surface profile even of the cast surface.

\subsection{Strength and Porosity Relationship for Pervious Recycled Aggregate Concrete}

Following the earlier discussion, it is clear that influence of age, specimen size and shape, binder material type on compressive strength of pervious concrete are not significant when compared with the influence of porosity of concrete. Figure 8 shows the correlation between compressive strength and porosity of pervious concrete and the exponential relationship showed very high degree of correlation. In these plots, the compressive strength results obtained with all six mixes using cubes and cylinders are combined. It is clear that for pervious concrete, the type of aggregate influenced the relationship between strength and porosity.

The following empirical equations for 28-day compressive strength are obtained for pervious concrete with natural and recycled aggregates. These equations could be used for the

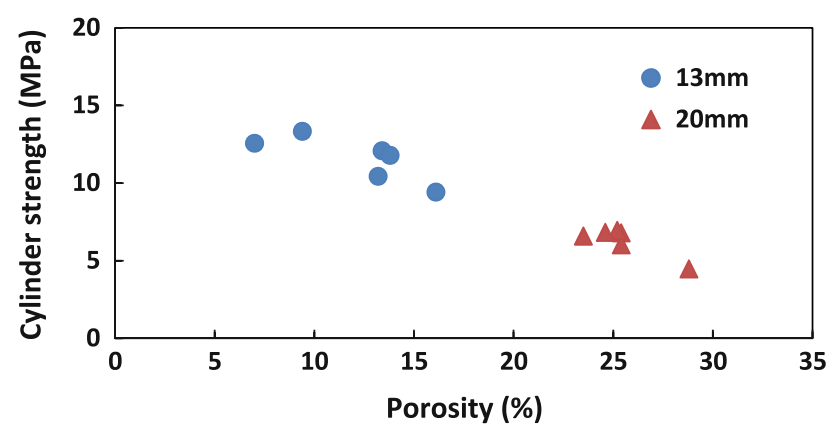

Fig. 5 Effect of aggregate size on the strength of recycled aggregate pervious concrete.

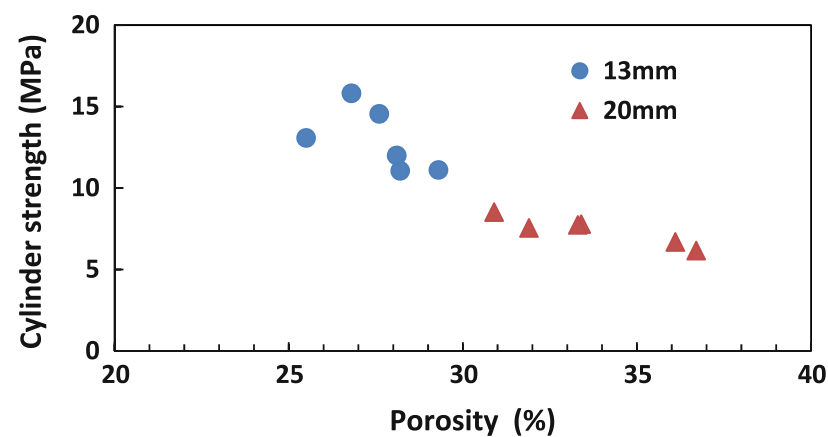

Fig. 6 Effect of aggregate size on the strength of natural aggregate pervious concrete. 
mix design of pervious concrete with either natural or recycled concrete aggregates. The correlation coefficient for these two equations was 0.95 , indicating a high degree of correlation between compressive strength and porosity, independent on the type of aggregate.

For natural aggregate: $f_{n}=70.2 \mathrm{e}^{-0.066 P}$

For recycled concrete aggregate: $f_{r}=22.2 \mathrm{e}^{-0.052 \mathrm{P}}$

where $f_{n}$ and $f_{r}$ are the 28-day compressive strength for natural and recycled pervious concrete, respectively and $\mathrm{P}$ is the porosity of the pervious concrete mix.

\subsection{Permeability of Pervious Concrete}

Table 4 shows the mean permeability of pervious concrete using falling head method. The permeability of pervious concrete with $20 \mathrm{~mm}$ natural aggregate was $26.7 \mathrm{~mm} / \mathrm{s}$ is the

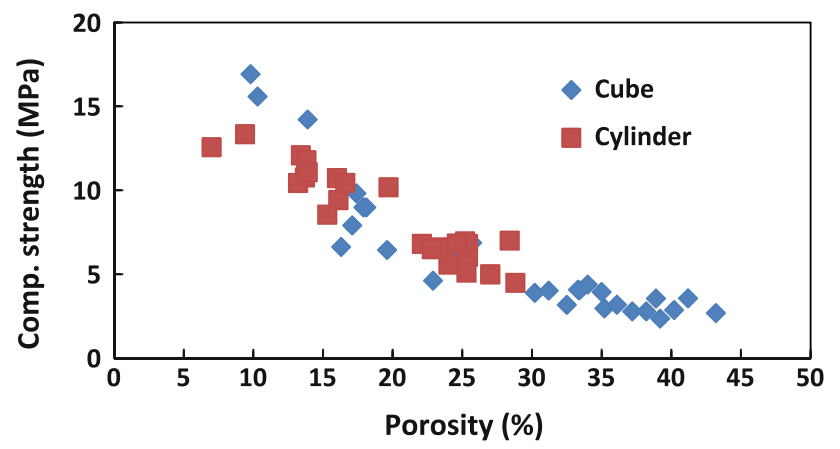

Fig. 7 Effect of test specimens shape on the strength of recycled pervious concrete.

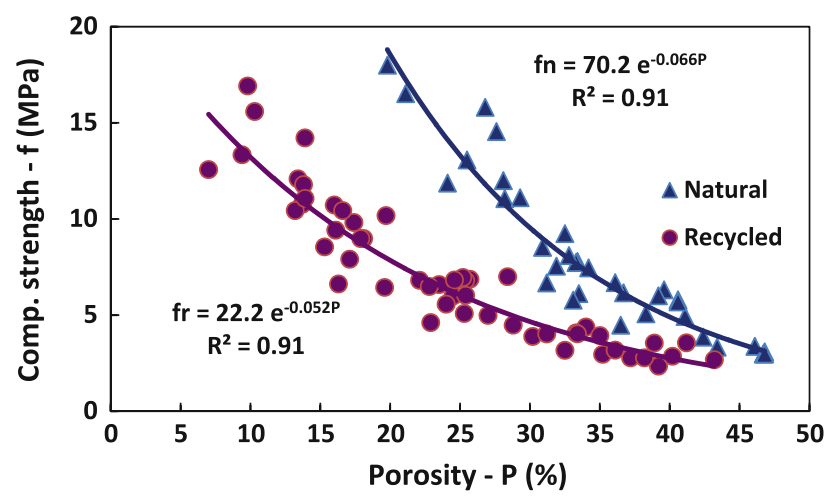

Fig. 8 Effect of aggregate type on the strength and porosity relationship for pervious concrete. highest due to the highest porosity of $35.9 \%$. The lowest permeability of $7.45 \mathrm{~mm} / \mathrm{s}$ was recorded with the pervious concrete with $13 \mathrm{~mm}$ recycled concrete aggregate which had the lowest porosity of $22 \%$.

Figure 9 shows the relationship between porosity and permeability for pervious concrete as a function of the water head. As expected, the water permeability of pervious concrete is sensitive to pressure head when the porosity is more that $25 \%$. The variation in the permeability with water head is observed for pervious concrete with both natural and recycled concrete aggregates. Considering the water level of $300 \mathrm{~mm}$, the permeability of pervious concrete for the falling head from 300 to $200 \mathrm{~mm}$ could be used for the mix design of pervious concrete, to meet the specification requirements.

Figure 10 shows the relationship between permeability coefficient (PC) and porosity $(\mathrm{P})$ for pervious concrete under

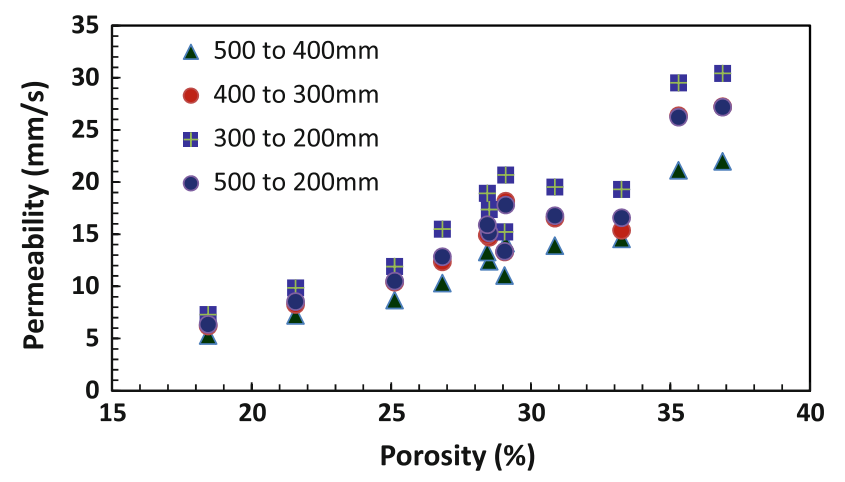

Fig. 9 Effect of head on the permeability and porosity relationship for pervious concrete.

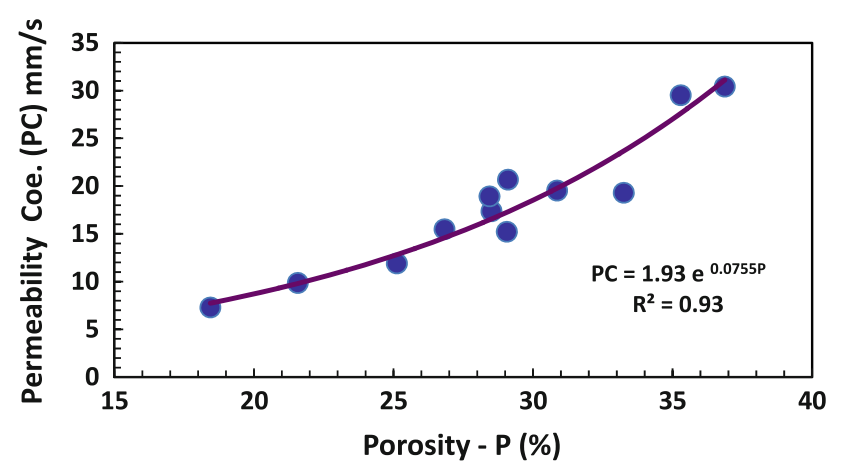

Fig. 10 Relationship between permeability and porosity for pervious concrete.

Table 4 Mean Porosity and permeability of pervious concrete.

\begin{tabular}{c|c|c|c}
\hline Mix & Density $\left(\mathrm{kg} / \mathrm{m}^{3}\right)$ & Porosity (\%) & Permeability $(\mathrm{mm} / \mathrm{s})$ \\
\hline \hline NA20 & 1610 & 35.9 & 26.7 \\
\hline NA13 & 1780 & 28.5 & 15.5 \\
\hline RA20 & 1540 & 29.1 & 15.6 \\
\hline RA13 & 1650 & 22.0 & 7.45 \\
\hline RA13S35 & 1385 & 32.4 & 17.1 \\
\hline RA13S70 & 1535 & 24.6 & 9.78 \\
\hline
\end{tabular}


the water head of $300 \mathrm{~mm}$ and the Eq. (5) shows the empirical equation. The type of aggregate has no significant effect on the permeability of pervious concrete.

$$
\mathrm{PC}=1.93 \mathrm{e}^{0.0755 \mathrm{P}}
$$

\subsection{Mix Design for Pervious Concrete}

Figure 11 shows the relationships among porosity, strength and permeability for pervious concrete, developed using the Eqs. (3 to 5), as a function of the aggregate type. For a given porosity, Fig. 11 could be used to estimate the strength and permeability of pervious concrete. As an example, at the specified porosity of $20 \%$, pervious concrete will have the water permeability of $8.5 \mathrm{~mm} / \mathrm{s}$ (or 30.6 cu. m. of water drainage through 1 sq. $\mathrm{m}$. area in an hour) and the expected 28-day compressive strength of pervious concrete will be $19 \mathrm{MPa}$ and $8 \mathrm{MPa}$ with natural aggregate and recycled concrete aggregate, respectively.

In the process of mix design of pervious concrete with either natural aggregate or recycled concrete aggregate, Fig. 11 could be used to obtain the void content needed for trial mixes to satisfy the specification requirement for water permeability and compressive strength of concrete. Once the void content is known, simple mathematical approach can be used to determine the mix composition using volumetric calculations

\section{Conclusions}

Based on the experimental investigation on the pervious recycled aggregate concrete with high fineness ground granulated blast furnace slag, the following conclusions could be made:

1. Compressive strength of pervious concrete depends primarily on the porosity of concrete; Age, binder materials type and test specimen shape and size showed marginal influence on the strength of pervious concrete for a given porosity.

2. Reduction in the aggregate size decreased the porosity of pervious concrete and as the consequence the strength of pervious concrete is increased.

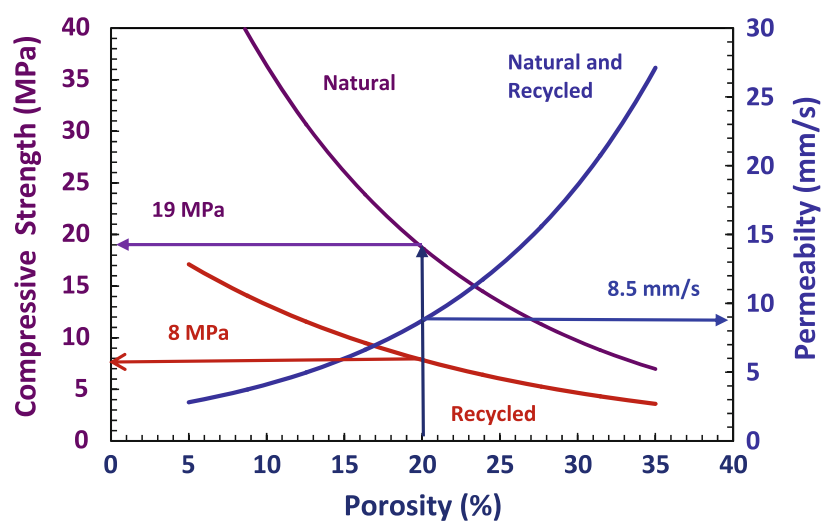

Fig. 11 Relationships among porosity, strength and permeability for pervious concrete.
3. For a given porosity, recycled concrete aggregate had reduced the compressive strength of pervious concrete; the influence of aggregate type on strength is nonlinearly reduced with the increase in the porosity.

4. Permeability of pervious concrete is influenced by the porosity and the use of recycled concrete aggregate had no significant effect on the permeability of pervious concrete.

5. The relationship between compressive strength (f) and porosity (P) are given by the following empirical equations: for pervious natural aggregate concrete: $\mathrm{f}_{\mathrm{n}}=70.2 \mathrm{e}^{-0.066 \mathrm{P}}$; for pervious recycled aggregate concrete: $f_{r}=22.2 \mathrm{e}^{-0.052 \mathrm{P}}$

6. The relationship between permeability (PC) and porosity $(\mathrm{P})$ is not affected by the aggregate type and given by $\mathrm{PC}=1.93 \mathrm{e}^{0.0755 \mathrm{P}}$.

\section{Open Access}

This article is distributed under the terms of the Creative Commons Attribution License which permits any use, distribution, and reproduction in any medium, provided the original author(s) and the source are credited.

\section{References}

ACI Committee 522. (2006). Pervious concrete. Report No. 522R-06, American Concrete Institute. Detroit, USA, 2006, $25 \mathrm{p}$.

Aoki, Y., \& Sriravindrarajah, R. (2008). Shrinkage of environmentally friendly sustainable porous concrete. In Proceedings of the international conference on sustainable concrete construction. Ratnagiri, India, February 2008.

Aoki, Y., Sriravindrarajah, R., \& Khabbaz, H. (2008). Environmentally friendly sustainable pervious concrete. In Proceedings of the 20th Australasian conference on the mechanics of structures and materials, Toowoomba, Australia, December 2008.

Aoki, Y., Sriravindrarajah, R., \& Khabbaz, H. (2009). Effect of fly ash performance of pervious concrete. In Supplementary proceeding of tenth CANMET/ACI international conference on recent advances in concrete technology and sustainability issue. Seville, Spain, August 2009.

Aoki, Y., Sriravindrarajah, R., \& Khabbaz, H. (2012). Properties of pervious concrete containing fly ash. Road Materials and Pavement Design, 13(1), 1-11.

Malhotra, V. M. (1976). No-fines concrete-Its properties and applications. Journal of the American Concrete Institute, 73(11), 628-644.

Meininger, R. C. (1988). No-fines pervious concrete for paving. Concrete International, 10(8), 20-27.

Mohboub, K. C., Canler, J., Rathbone, R., Robl, T., \& Davis, B. (2009). Pervious concrete: Compaction and aggregate gradation. ACI Materials Journal, 106(6), 523-528. 
Murao, K., Yuasu, Y., Misima, N., \& Hatanaka, S. (2002). Experimental study on the strength of porous concrete with low quality recycled aggregate. Journal of Architectural Institute of Japan, 8, 823-824.

Otani, T., Sato, Y., Kiyohara, C., Murakami, M., \& Mitsui, Y. (2005). An equation for predicting the compressive strength of porous concrete. Journal of Structural and Construction Engineering, 590, 25-30.

Schaefer, V. R., Wang, K., Suleiman, M. T., \& Kevern, J. T. (2006). Mix design development for pervious concrete in cold weather climates, Final Report, center for transportation research and education, Iowa State University, February $2006,85 \mathrm{p}$.

Sriravindrarajah, R., \& Aoki, Y. (2008). Environmentally friendly porous concrete. In Proceedings of the second international conference on advances in concrete and construction, Hyderabad, India, February 2008.

Sriravindrarajah, R., Nguyen L. D., Do, H. M., Aoki Y. (2010). Effect of clogging on the water permeability of pervious concrete. In Proceedings of the 21st Australasian conference on the mechanics of structures and materials (pp. 873-876), Melbourne, Australia, December 2010.
Sriravindrarajah, R., Stewart, M., \& Greco, D. (2001). Variability of recycled concrete aggregate and its effects on the properties of concrete. In Proceedings of the second international conference on engineering materials, August 2001, San Jose, USA.

Sriravindrarajah, R., \& Tam, C. T. (1985). Properties of concrete made with crushed concrete as coarse aggregate. Magazine of Concrete Research, 37(130), 29-38.

Sriravindrarajah, R., \& Tam, C. T. (1988). Methods of improving the quality of recycled aggregate concrete. In Proceedings of the second international RILEM symposium on demolition and reuse of concrete and masonry, November 1988, Japan.

Stormwater management handbook, US Environmental Protection Authority, Nov. 2009, 45p. http://www.epa.gov/smart growth/pdf/northern_kentucky_ch1-4.pdf.

Tennis, P. D., Leming, M. L., \& Akers, D. J. (2004). Pervious concrete pavements, Special publication by Portland Cement Association and The National Ready Mixed Concrete Association, USA, 2004. 